\title{
Ways of thinking about ways of being
}

\author{
BRADLEY RETTLER
}

\section{Introduction}

In many ways, I don't much resemble the computer on which I am typing this paper. It is shiny, draws electricity from an outlet, is playing the Hamilton soundtrack, is composed of many circuits and was produced in a variety of factories. Of course, we are alike in many ways as well. We are both in my office, we are both located in space, we are both physical objects, we both have a colour, and we both exist.

This latter claim - the claim that we both exist - comes from the thesis that everything exists, and exists in the same way. But there are some who think that not everything exists in the same way. Pluralists about being think that some things exist in different ways, or enjoy different ways of being. Of course, even Pluralists may think that my computer and I exist in the same way: ${ }^{1}$ Pluralism is often motivated by considerations of things even more different than my computer and me. Some Pluralists - for example Russell (1912, 91-100) and Moore (1903), 161-163 - think that concrete objects and abstract objects exist in different ways. Others - for example Aquinas (1947, q8, a3) - think that God and created things exist in different ways. What it takes to be a Pluralist is just to think that there is more than one way of being and, for each way of being, at least one thing exists in that way. ${ }^{2}$

Pluralism is at present the minority view; Monism, the view that there is just one way to be, reigns. And Pluralism has recently come under fire. Merricks (2019) has given three arguments against Pluralism. First, he argues that Pluralists who do not accept a way of being that everything has (hereafter 'generic existence') cannot state a Pluralism that posits a specific number of ways of being (Merricks 2019: §2). Second, he argues that Pluralists who do accept generic existence thereby undermine the main motivation for Pluralism, and that their view is especially vulnerable to a classic objection to Pluralism (Merricks 2019: §3, 601-2). Finally, he argues that since Pluralists can't accept generic existence (for the aforementioned reasons), they can't make claims about everything (594, 606). Builes (2019)

1 Exceptions can be found in McDaniel 2018: Chapter 6. McDaniel's Heidegger has it that there is a way of being (Existenz) had by all and only Daseins (and that being a Dasein is sufficient for being a person) (McDaniel 2018: 177). And a view he calls 'Individualistic Fragmentationalism' has it that each person enjoys a fundamental way of being that nothing else (and nobody else) enjoys (193). Both of these views have it that my computer and I exist in different ways.

2 I'll assume, just for ease of talking, that being and existing are the same thing. My apologies to Meinong. 
thinks that the Pluralist can respond to Merricks' arguments, but offers a dilemma to Pluralists concerning whether Pluralism is a fundamental fact.

In $\S 2$, I distinguish several versions of Pluralism. In $\S 3$, I show which version(s) of Pluralism can respond to Merricks' arguments. In §4, I show how the version of Pluralism that can respond to Merricks' arguments should respond to Builes' dilemma.

\section{The ways of thinking about ways of being}

It might seem like there is one way to think about Pluralism; it is the view that there is more than one way of being. According to the standard division, Monists think that there is only one way to be, and Pluralists think there are many ways to be. But that division is too coarse-grained to capture what many Pluralists believe. These Pluralists help themselves to the notion of naturalness - developed in Lewis 1983 - so it's worth saying a bit about naturalness before presenting the Pluralist views.

A predicate is more natural than another when the former 'carves nature at the joints' better than the latter does. ${ }^{3}$ For example, the predicate 'has mass' is more natural than the predicate 'has mass or is 2 metres tall'. The predicate 'is a dog' is more natural than the predicate 'is the tallest building in the first state to have a female governor'. Some predicates are perfectly natural. Perfectly natural predicates are the ones that carve nature perfectly at the joints. Perhaps 'has -1 charge' is perfectly natural.

The notion of naturalness might apply to predicates in virtue of those predicates referring to properties which are more or less or perfectly natural, or more or less or perfectly fundamental. (Fundamentality is akin to naturalness, and will play a role in $\S 4$.) But, as Lewis points out, even nominalists can believe in a notion of naturalness. We might wonder whether, in addition to predicates, naturalness applies to other bits of our language. Particularly relevant to this paper is the question of whether some quantifiers might be more or less natural than others, and whether there is a quantifier that is perfectly natural. ${ }^{4}$

One might think there is only one way to be. Or one might think there is only one perfectly natural way to be, and there are many ways that are less natural. Or one might think that there are many ways to be, all equally natural. (Or one might think something else.) Granted the notion of naturalness, we can formulate (at least) six views regarding being and whether there are ways of being.

3 See Sider 2011 for a recent discussion of what it means to carve nature at the joints. A helpful way to think about it is to think about what predicates God would use if you asked her to give the very best description of the world. Presumably for a mereological sum of hands and monuments' would not show up, but 'has negative charge' might.

This is the question of Sider 2009: $\$ 10$ and Sider 2011: especially Chapter 9. 
(WB1) There is only one way to be, and everything that exists exists in that way.

(WB2) There is only one perfectly natural way to be, and everything that exists exists in that way; there are other ways of being, but they are less natural than the one way to be such that everything exists in that way. (WB3) There are many ways to be, and no way to be is more natural than any other.

(WB4) There are many ways to be, none of which is more natural than any other, and one way to be such that everything exists in that way, and the way to be such that everything exists in that way is less natural than every other way to be.

(WB5) There are many ways to be and one way to be such that everything exists in that way, and none of those is more natural than any other. (Builes (2019: §5) calls this 'Hybridism'.)

(WB6) There are no ways to be, or if there are, nothing exists in any of the ways to be that there are.

It turns out that many of these views have been adopted. van Inwagen (1998), 236ff and Merricks (2019) accept (WB1), Sider (2011: §5.3) and Korman (2015: 48, 87-88) might be taken to accept (WB2), Turner's Pluralist (Turner 2010: especially 7-9) and Moore (1903), 161-163 accept (WB3), McDaniel's Heidegger (McDaniel 2018: $\$ 1.2$, especially 24) accepts (WB4), McDaniel's Meinong, who adds a generic way of being ('Quasisein') that '. . . has as much right to be regarded as a fundamental expression as the two inner ones' to existence and subsistence, accepts (WB5) (McDaniel 2018: 37-38) and Hawthorne and Cortens (1995) and Turner (2011) accept (WB6).

(WB1) is Monism. (WB3) is obviously (a version of) Pluralism. But (WB4) also seems like (a version of) Pluralism, as does (WB5). (WB6) is Nihilism. (WB2) is somewhere between Monism and Pluralism, and it could be classified as either.

I now turn to Merricks' arguments against Pluralism. I think the arguments succeed against (WB3), but not against (WB4).

\section{Merricks' arguments}

Merricks (2019) first offers a dilemma against a particular version of Pluralism - Pluralism that believes in exactly two ways of being. Let's call such a view 'Pluralism-2'. The dilemma is:

(Merricks' Dilemma) Does a Pluralist-2 also accept that there's a generic way of being such that everything exists in that way? (Merricks 2019: §2) 
If not, he argues, the Pluralist-2 can't state Pluralism-2, nor can she make claims about everything. If so, he argues, then that (i) undermines the classic motivation for Pluralism, (ii) makes Pluralism especially vulnerable to a classic objection and (iii) is inconsistent with what Pluralists have said.

Although we'll take the second horn, let us briefly examine the first horn. The Pluralist- 2 wants to say that there are two ways of being. She will also presumably want to say that everything enjoys one of those two ways of being, and that each of those two ways of being has something that exists in that way. ${ }^{5}$ Otherwise it is consistent with Pluralism-2 that nothing exists, or that everything enjoys just one way of being, or that some things exist in some third way of being. The natural way of stating Pluralism-2 in first-order logic, with subscripts to denote different quantifiers corresponding to different ways of being, is:

$$
\left(\text { PluRAlism-2) } \forall x\left(\exists_{1} y(y=x) \vee \exists_{2} y(y=x)\right) \wedge \exists_{1} x(x=x) \wedge \exists_{2} x(x=x)^{6}\right.
$$

But there is a generic unrestricted quantifier in Pluralism-2. And the first horn of the dilemma doesn't allow for a generic unrestricted quantifier. The Pluralist-2 who accepts the first horn must re-state Pluralism-2, perhaps as something like:

$$
\begin{aligned}
& (\text { PluRAlism }-2 *) \forall_{1} x\left(\exists_{1} y(y=x) \vee \exists_{2} y(y=x)\right) \wedge \forall_{2} x\left(\exists_{1} y(y=x) \vee \exists_{2} y(y=x)\right) \\
& \wedge \exists_{1} x(x=x) \wedge \exists_{2} x(x=x)^{7}
\end{aligned}
$$

But Pluralism-2* doesn't rule out some third (or fourth, or fifth, or ...) way of being that some things enjoy. And it doesn't rule out things existing 1 and existing 2 . So, Merricks concludes, the first horn of the dilemma is not an option for the Pluralist-2 (Merricks 2019: 596). And the same goes for Pluralism- $n$, for any $n$. A statement of it won't rule out some $n+1$ way of being, or things existing in multiple of the ways of being.

But note, as Merricks does, that while this dilemma generalizes to Pluralism- $n$, for any $n$, it doesn't generalize to all Pluralisms. A Pluralist needn't be a Pluralist- $n$, for some $n$. One could just be a Pluralist. One could also think there are at least two ways of being, and not take a stand on how many. That position can be stated (Merricks 2019: 606). Indeed, it is the very position stated in PluRalism- $2 *$. One could think there are at least $n$ ways of being, for any $n$, and state that position. What Merricks' dilemma

5 She may also want to say that everything enjoys exactly one of those two ways of being. This stronger view would require modifications of the statements of Pluralism to follow.

6 In English: everything that exists either exists or exists $_{2}$, and something exists ${ }_{1}$ and something exists 2 . The stronger version would add ' $\wedge \neg \exists_{1} x \exists_{2} y(y=x)$ '.

7 In English: everything that exists either exists $_{1}$ or exists ${ }_{2}$, and everything that exists ${ }_{2}$ either exists $_{1}$ or exists $s_{2}$, and something exists ${ }_{1}$ and something exists 2 . Again the stronger version would require the addition of ' $\wedge \neg \exists_{1} x \exists_{2} y(y=x)$ '. 
shows us is that Pluralists can't state that there are exactly $n$ ways to be, for any $n$, without a generic unrestricted quantifier. And it shows us that Pluralists can't state that there are no more than $n$ ways to be, for any $n$, without a generic unrestricted quantifier.

So the Pluralist- $n$ (for any $n$ ) and the Pluralist who wants to say that there are no more than $n$ ways to be (for any $n$ ) will want a generic unrestricted quantifier. They will need to take the second horn of the dilemma. The first horn ruled out PluRalism-2, but the second horn of the dilemma accepts that there is a generic unrestricted way of being such that everything exists in that way, which is formally represented by ' $\exists$ ' and ' $\forall$ '. So PLuRALism- 2 is back on the table as a statement of Pluralism-2, and taking the second horn allows us to make claims about everything.

Merricks gives three reasons that the Pluralist shouldn't accept a generic unrestricted quantifier. One reason is that 'virtually all Pluralists of the past' have not accepted a generic unrestricted quantifier (Merricks 2019: 603-4). I won't try to respond to this reason. Perhaps someone could do some exegetical history of philosophy to show that, armed with a notion of naturalness, (WB4) would have been acceptable to past Pluralists; I will not try to do so. I will deal with the other two reasons, and concede to Merricks that past Pluralists would not have liked (WB4). Nevertheless, if it can help us resolve Merricks' and Builes' dilemmas, it might be the best version of Pluralism.

The second reason that Merricks says a Pluralist shouldn't accept a generic unrestricted way of being is that accepting a generic unrestricted way of being undermines the motivation for Pluralism - that concrete and abstract things are so different as to not enjoy a single way of being, that God and creation are so different as to not enjoy a single way of being, and the like $(601,603)$. In response, I think the (WB4) Pluralist can still state this reason, or at least say something that captures the intuition behind it. Although (WB4) Pluralism accepts that there is a way of being that concrete and abstract things both enjoy, it says that that is not a very natural way of being. It's less natural, in any case, than the way of being that all and only concrete things enjoy and it's less natural than the way of being that all and only abstract things enjoy. It is, as McDaniel (2018: 28) puts it, 'akin to a mere disjunction of the metaphysically basic ways of being. ${ }^{8}$ So although the Pluralist who accepts a generic unrestricted way of being that everything enjoys can't say that concrete and abstract things are so different that there

8 The (WB4) Pluralist then needs to say precisely what being akin to a mere disjunction is. Merricks (2019: 11) argues that it cannot be being a mere disjunction. McDaniel (2018) gives examples of features that are akin to mere disjunctions: being healthy, being flexible and being elegant. These are analogous features; 'they enjoy a kind of unity that merely disjunctive features lack: their specifications are, to put it in medieval terms, unified by analogy' (51). So, for McDaniel, to be akin to a mere disjunction is to be an analogous feature. Most of Chapter 2 of The Fragmentation of Being is dedicated to exploring what it is to be an analogous feature and whether being is an analogous feature. 
is no way of being that they both enjoy, she can say that concrete and abstract things are so different that the way of being that they both enjoy is quite unnatural.

The third reason Merricks says a Pluralist shouldn't accept a generic unrestricted way of being is that it increases Pluralism's vulnerability to an objection to Pluralism. That objection is that 'pluralists posit a difference in being where there is instead but a difference in kind among entities that exist in the same way' (602-3). Once one accepts a generic unrestricted way of being that everything enjoys, then since presumably one also accepts predicates like 'is abstract' and 'is concrete' and 'is divine' and 'is created' and so on, one can make the distinctions that the Pluralist wants to make without the extra quantificational apparatus - without positing ways of being. In response, I think the (WB4) Pluralist should agree that one can distinguish objects by using predicates instead of quantifiers. However, she can say that this is a less natural, less joint-carving way of putting things. The generic quantifier is less natural than the others, and so any sentence that uses the generic unrestricted quantifier is less natural than a sentence that refers to one of the ways of being that not everything enjoys. The book of the world, then, contains quantifiers referring to the many ways of being - not the generic unrestricted quantifier.

So I conclude that Merricks has shown that the Pluralist who doesn't accept a generic unrestricted quantifier cannot state a Pluralism that posits a particular number of ways of being nor can she state a Pluralism that posits a maximum number of ways of being, though she can state a Pluralism that posits a lowest number of ways of being. The Pluralist who does accept a generic unrestricted quantifier can make claims about everything, and so she can state a Pluralism that posits a particular number of ways of being and she can state a Pluralism that posits a maximum number of ways of being. But in order to respond to Merricks' objections to Pluralists that accept a generic unrestricted quantifier, such a Pluralist - a (WB4) Pluralist - ought to go in for talk of naturalness and/or fundamentality. For the sake of simplicity, I'll suppress the '(WB4)' for the rest of the paper and assume we're talking about (WB4) Pluralism.

\section{Builes' dilemma}

Builes issues an additional dilemma to pluralists:

(Builes' dilemma) Is [Pluralism-2] a fundamental fact? (Builes 2019: 399)

The dilemma assumes two principles about fundamentality that come from Sider (2011):

(PURITY) Fundamental facts only contain fundamental notions. 
(COMPLETENESs) Every non-fundamental truth holds in virtue of some fundamental truth. ${ }^{9}$ (Builes 2019: 398)

To further explain CompletenEss, Sider (2011) introduces the notion of metaphysical semantics. A metaphysical semantics gives truth-conditions for non-fundamental facts that appeal only to fundamental facts. So, for a sentence $S$ in a language $L$ that contains non-fundamental expressions, a metaphysical semantics for $L$ contains something of the form: $S$ is true in $L$ iff $\phi$, where $\phi$ contains no non-fundamental expressions. In this way sentences with non-fundamental terms can be true, but made true by fundamental things in virtue of having a metaphysical semantics that gives truthconditions that only refer to those fundamental things. The metaphysical semantics - the statements of the form ' $S$ is true in $L$ iff $\phi$ ' - are not fundamental, since they include the sentences (' $S$ ' above) that have non-fundamental expressions; so their being fundamental would violate PURITY. But the truth-conditions (' $\phi$ ' above) are fundamental.

So should Pluralists say that PluRAlism-2 is a fundamental fact?

If the Pluralist says 'yes', then, given Purity, every expression in Pluralism2 has to be a fundamental expression. There is a generic unrestricted universal quantifier in Pluralism-2. So, given PuRITY, the generic unrestricted universal quantifier is fundamental. We can define the generic unrestricted existential quantifier in terms of the generic unrestricted universal quantifier. So it seems that the Pluralist must accept that the generic unrestricted existential quantifier is fundamental.

Builes thinks saying 'yes' and accepting that the generic unrestricted existential quantifier is fundamental comes at a high price. But accepting that the generic unrestricted quantifier is fundamental doesn't entail believing that no other quantifier is fundamental, or as fundamental. It is open to one who accepts (WB5) to accept this - the generic unrestricted existential quantifier is just as fundamental as the many other ways of being. Perhaps Builes' argument gives us some reason to accept (WB5). Builes does, however, argue against (WB5) in $§ 5$, saying that it is less parsimonious and undermines the Pluralist response to Merricks' arguments; so perhaps it will not turn out to be better than (WB3) or (WB4).

But consider the second horn: saying 'no'. Then, by CompleTENEss, Pluralism-2 must have a metaphysical semantics, and truth-conditions for PLURALISM-2 must contain only fundamental expressions. The generic unrestricted existential quantifier and the generic unrestricted universal quantifier, we are supposing, are not fundamental expressions. So a metaphysical semantics for PLURALISM-2 cannot make use of them in giving truth-conditions for PluRAlism-2.

9 Of course, one could avoid Builes' dilemma by rejecting either or both of these. See Merricks 2013: $\$ 2$ for an argument against the conjunction of PURITY and COMPLETENESS. 
Builes says that the Pluralist cannot give a metaphysical semantics for Pluralism-2. He rests this on an argument from Merricks, saying 'the Pluralist must give the truth conditions for the claim that everything either exists ${ }_{1}$ or exists 2 using only fundamental notions that do not include the notion of generic existence. But wait - this is the very task that Merricks argued that Pluralists cannot do!' (Builes 2019: 399). The argument from Merricks that Builes is referring to is the argument that the Pluralist who doesn't accept a generic unrestricted quantifier cannot state a Pluralism that posits exactly $n$ ways of being, for any $n$ (Merricks 2019: §2). And, given Purity, truth-conditions for Pluralism-2 cannot contain a generic unrestricted quantifier.

First, I respond that the Pluralist can still give truth-conditions for the claim that there is more than one way of being. She can say that there are at least two ways of being such that at least one thing exists in each way. And that can be a fundamental fact. That may be enough for many Pluralists.

Second, I suggest, the Pluralist- 2 can give truth-conditions for the claim that everything either exists ${ }_{1}$ or exists 2 using only fundamental notions that do not include the notion of generic existence. A metaphysical semantics has four components: the sentence $S$, the language $L$, the truth-conditions $\phi$, and the statement that $S$ is true in $L$ iff $\phi$. (The statement that $S$ is true in $L$ iff $\phi$ is what I'm calling the metaphysical semantics for $S$.) In the present case, $S$ is Pluralism-2, $L$ is English, $\phi$ is Pluralism- $2 *$, and the metaphysical semantics is that Pluralism-2 is true in English iff Pluralism-2*. $S$ must contain nonfundamental terms, and Pluralism- 2 does. $\phi$ must not contain fundamental terms, and Pluralism- $2 *$ does not. What about the metaphysical semantics? Clearly it needn't contain only fundamental terms, since it contains $S$, which must contain non-fundamental terms.

The task is to give a sentence for $\phi$ that's (1) true iff Pluralism-2 is true and (2) doesn't use generic existence. That sentence is Pluralism-2*. It clearly meets condition (2). Does it meet condition (1)? That is, is the following true?

$$
\begin{aligned}
\text { MSP: } & \forall x\left(\exists_{1} y(y=x) \vee \exists_{2} y(y=x)\right) \wedge \exists_{1} x(x=x) \wedge \exists_{2} x(x=x) \Leftrightarrow \forall_{1} x\left(\exists_{1} y(y\right. \\
& \left.=x) \vee \exists_{2} y(y=x)\right) \wedge \forall_{2} x\left(\exists_{1} y(y=x) \vee \exists_{2} y(y=x)\right) \wedge \exists_{1} x(x=x) \wedge \exists_{2} x(x \\
& =x)
\end{aligned}
$$

The Pluralist-2 thinks that MSP is true. This is because she thinks that Pluralism- $2 *$ in the fundamental language is true when and only when Pluralism-2 is true in English. In the fundamental language, $\exists_{1}$ and $\exists_{2}$ and $\forall_{1}$ and $\forall_{2}$ quantify over everything, and they are not the same quantifier. And whether MSP is true must be judged by the Pluralist-2's own lights. The Monist cannot demand that the Pluralist- 2 rule out Monism in the fundamental language by using the generic unrestricted quantifier that the Pluralist-2 doesn't believe is a part of the fundamental language! That is to beg the question against the Pluralist-2. So it meets condition (1). 
So Pluralism-2* gives Pluralist-friendly truth-conditions for PluRalism-2 that contain no non-fundamental expressions; in particular, Pluralism-2* doesn't use a generic unrestricted quantifier. The Pluralist- 2 believes that everything either exists ${ }_{1}$ or exists 2 . So in PluRAlism- $2 *$, by using $\forall_{1}$ and $\forall_{2}$, she is quantifying over everything - even though she's not saying that she's quantifying over everything. So the task is done.

Why does Builes claim that Merricks has shown that the Pluralist cannot do this? Merricks does consider Pluralism-2*. But he does not say that it fails to state truth-conditions for PLuRALISM-2. Rather, he says it will not work as a statement of Pluralism-2. He says this because it is consistent with varieties of Pluralism that accept more than two ways of being. So, he says, it will not work as a statement of a Pluralism that accepts only two ways of being.

But, to respond to Builes' dilemma, we do not need to state Pluralism-2 in a way that Monists and Pluralists- $n$ (for $n \neq 2$ ) cannot accept; we have already stated it with Pluralism-2. To respond to Builes' dilemma, we must give a metaphysical semantics for PluRAlism-2: we must give Pluralist-friendly truthconditions for PluRAlism-2 that contain no non-fundamental expressions. PluRALISM-2* does that. To demand that we offer a metaphysical semantics for Pluralism-2 that Monists and Pluralists- $n$ (for $n \neq 2$ ) cannot accept is to demand that the Pluralist-2 rule out Monism and Pluralism- $n$ (for $n \neq 2$ ) in the fundamental language. But that demand is unreasonable. As McDaniel (2018: 134) puts it, in the fundamental language we have to be able to 'show' that Monism and Pluralism- $n$ (for $n \neq 2$ ) are false, even though in the fundamental language we can't 'say' that they are false. The statement of Pluralism-2 should rule out Monism and Pluralism- $n$ (for $n \neq 2$ ). But that statement doesn't have to be a fundamental truth - only truth-conditions for Pluralism-2 do.

Compare the following example. Suppose someone believes that only mereological simples exist, and she believes that the predicate 'is a part of' does not show up in the fundamental language. She would state her view as 'Everything lacks proper parts.' But she would not think that is a fundamental truth, if she accepts PURITY, since it contains a non-fundamental expression. So it must have a metaphysical semantics. But the truth-conditions for 'Everything lacks proper parts' can't talk about proper parthood, and so can't say that nothing has proper parts. But that doesn't show that it can't be true, or that it can't be stated, or that it doesn't have a metaphysical semantics. It just can't be stated in the fundamental language. But the fundamental language shouldn't have to talk about all the non-fundamental stuff; indeed, it cannot. The situation is similar with Pluralism. PluRAlism-2* talks about everything, but it doesn't say that it's talking about everything. And it shouldn't have to, since the (WB4) Pluralist doesn't think that the generic quantifier - the quantifier that can quantify over everything - is fundamental. ${ }^{10}$

10 A Pluralist who thinks that the generic quantifier is fundamental (a (WB2) Pluralist and maybe a (WB3) Pluralist) would respond to Builes' dilemma by taking the first horn. 
Here's a similar example. Suppose someone believes that only mereological simples are quantified over by the fundamental quantifier. She also thinks the sentence 'There are tables' is true in English, so she gives a metaphysical semantics for it: 'There are tables' is true in English iff some simples stand in relations R1, R2, R3, .. The table-believer could insist that that doesn't guarantee that there are tables, since it doesn't say that there are tables. But that is to beg the question against this kind of mereological nihilist.

So, I conclude, the Pluralist can solve Builes' dilemma. PluRAlism-2 is true, but not fundamental. Pluralism-2* is a statement of truth-conditions for Pluralism-2 in the fundamental language. It doesn't work as a statement of Pluralism-2, but in the fundamental language one needn't be able to state Pluralism-2.

\section{Conclusion}

There are many ways of being an ontological pluralist. ${ }^{11}$ One way of being an ontological pluralist is to accept a generic unrestricted quantifier and a notion of naturalness or fundamentality, and say that the generic unrestricted quantifier is less natural or less fundamental than the quantifiers for the many ways of being. Those who do are able to solve both Merricks' and Builes' dilemmas. ${ }^{12}$

Department of Philosophy \& Religious Studies University of Wyoming Dept. 3392, 1000 E. University Ave Laramie, WY 82071, USA rettlerb@gmail.com

\section{References}

Aquinas, T. 1947. Summa Theologiae. Trans. the Fathers of the English Dominican Province. http://www.sacred-texts.com/chr/aquinas/summa/index.htm.

Builes, D. 2019. Pluralism and the problem of purity. Analysis 79: 394-402.

Caplan, B. 2011. Ontological superpluralism. Philosophical Perspectives 25: 79-114.

Hawthorne, J.O. and A. Cortens. 1995. Towards ontological nihilism. Philosophical Studies 79: 143-65.

Korman, D.Z. 2015. Objects: Nothing out of the Ordinary. Oxford: Oxford University Press.

11 This is the thesis of Caplan 2011, though Caplan's concern is more historically focused on what Pluralists have said rather than what options they have.

12 Thanks to Trenton Merricks and Andrew Bailey for extensive comments and discussion, and Alex Skiles and the students in my Spring 2019 metametaphysics seminar at the University of Wyoming for discussion. 
Lewis, D. 1983. New work for a theory of universals. Australasian Journal of Philosophy 61: 343-77.

McDaniel, K. 2018. The Fragmentation of Being. Oxford: Oxford University Press.

Merricks, T. 2013. Three comments on Writing the Book of the World. Analysis Reviews 73: 722-36.

Merricks, T. 2019. The only way to be. Noûs 53: 593-612.

Moore, G.E. 1903. Principia Ethica. Cambridge: Cambridge University Press.

Russell, B. 1912. The Problems of Philosophy. London: Williams and Norgate. (Paperback edition Oxford University Press, 1959)

Sider, T. 2009. Ontological realism. In Metametaphysics, eds. D. Chalmers, D. Manley and R. Wasserman. Oxford, 384-423: Oxford University Press.

Sider, T. 2011. Writing the Book of the World. Oxford: Oxford University Press.

Turner, J. 2010. Ontological pluralism. Journal of Philosophy 107: 5-34.

Turner, J. 2011. Ontological nihilism. In Oxford Studies in Metaphysics, vol. 6, eds. D. W. Zimmerman and K. Bennett, 3-55. Oxford: Oxford University Press.

van Inwagen, P. 1998. Meta-ontology. Erkenntnis 48: 233-50. 


\section{Abstract}

Monism about being says that there is one way to be. Pluralism about being says that there are many ways to be. Recently, Trenton Merricks and David Builes have offered arguments against Pluralism. In this paper, I show how Pluralists who appeal to the relative naturalness of quantifiers can respond to these arguments.

Keywords: metaphysics, ontology, being, naturalness, ontological pluralism 